\title{
Original mixed methods research
}

\section{Development of a prenatal program for adults with personal histories of childhood abuse or neglect: a Delphi consensus consultation study}

\section{Nicolas Berthelot, PhD (1,2); Roxanne Lemieux, PhD (1,2); Carl Lacharité, PhD (1,2)}

This article has been peer reviewed.

\section{Abstract}

Introduction: Pregnancy and the birth of a child present particular challenges for adults with personal histories of childhood abuse or neglect. However, few prenatal interventions address the specific needs of this population. This research aims to determine a list of actions that should be achieved during group interventions designed for expectant parents who experienced childhood trauma.

Methods: Fifteen stakeholders representing nine different Quebec health care and community organizations that work with families and/or trauma survivors participated in a Delphi process in two rounds. In round 1, three project leaders identified, from clinical and empirical literature, a set of 36 actions relevant for expectant parents who experienced childhood trauma. Using an anonymized online survey, stakeholders coded how important they considered each action and whether they were already conducting similar interventions in their clinical setting. Stakeholders subsequently participated in a one-day in-person meeting during which they discussed the pertinence of each action, proposed new ones and refined them. This was followed by a second anonymized online survey (round 2). A consensus was reached among the stakeholders regarding a final list of 22 actions.

Results: Two central clusters of actions emerged from the consultation process: actions aiming to support mentalization about self and parenthood, and actions aiming to support mentalization of trauma.

Conclusion: The Delphi process helped to identify what should be the core of a prenatal intervention targeting adults who experienced childhood trauma, from the viewpoint of professionals who will ultimately deliver such a program.

Keywords: adult survivors of child adverse events; child maltreatment; parenting; intervention; mentalization; Delphi process

\section{Introduction}

Pregnancy and the year following childbirth is a critical transitional period-a time of risk and opportunities. The level of adaptation that pregnancy and the birth of a child requires makes this one of the most critical periods for a woman's mental health. ${ }^{1}$ Such an important life transition is a challenge even for adults with no apparent biological, psychological, marital or socioeconomic vulnerabilities. The challenge associated with pregnancy or birth may be even more intense for adults who experienced adverse life events, such as childhood abuse or neglect.

\section{Highlights}

- Childhood abuse or neglect have long-term impacts that persist throughout adulthood and negatively affect the transition to parenthood.

- Few interventions are designed for the numerous adults with histories of childhood abuse and neglect who are expecting.

- Such interventions are of great importance for public health because they could promote the physical and mental health of adults with personal histories of childhood trauma, promote the psychosocial development of their child, and interrupt intergenerational cycles of abuse.

- Stakeholders targeted to offer such a program consider that its primary focus should be to support mentalization of self and parenthood and mentalization of trauma.

There is extensive evidence confirming that childhood abuse and neglect have mental $^{2,3}$ and physical health ${ }^{4,5}$ consequences that persist into adulthood. Disorders in adults associated with childhood trauma include major depressive disorder, anxiety disorder, conduct disorder, posttraumatic stress disorder, substance use disorder, obesity, arthritis, high blood pressure, migraine headaches, cancer and strokes. Pregnancy and the birth

\section{Author references:}

1. Université du Québec à Trois-Rivières, Trois-Rivières, Québec, Canada

2. Centre d'études interdisciplinaires sur le développement de l'enfant et la famille, Trois-Rivières, Quebec, Canada

Correspondence: Nicolas Berthelot, Département des sciences infirmières, Université du Québec à Trois-Rivières, C.P. 500, Trois-Rivières, QC G9A 5H7; 
of a child may trigger or intensify these latent or apparent disorders. ${ }^{6}$

Pregnant women with personal histories of childhood trauma are at increased risk of significant challenges, pain and distress. They are also at increased risk of having limited access to personal and social protective factors. Expecting a child may resurrect unresolved attachment trauma; ${ }^{7}$ such non-mentalized trauma (i.e. trauma that are denied, reported incoherently or for which the victim takes the blame) have been associated with negative feelings towards the baby and motherhood, and difficulties in intimate relationships. ${ }^{8}$ Women who experienced childhood trauma report common complaints of pregnancy significantly more often ${ }^{9}$ and are more likely to have a highrisk pregnancy. ${ }^{10,11}$ In addition, they are more at risk of intimate partner violence than pregnant women who have not experienced childhood trauma. ${ }^{12,13}$ They are also at greater risk of trauma-related symptoms, such as dissociation and symptoms of posttraumatic stress disorder, ${ }^{14}$ as well as symptoms not specific to trauma, such as anxiety and depression. ${ }^{15,16}$

The strategies often used to regulate intense negative emotions in adults with a history of trauma (e.g. dissociation, avoidance, psychoactive medication, alcohol or drug use/abuse) may actually interfere with parenting or affect the fetus and eventually the child. Women who experienced maltreatment in childhood are more inclined to be isolated during pregnancy ${ }^{17}$ and in the years following childbirth, ${ }^{18}$ and to report low satisfaction with the social support they receive. ${ }^{19}$

Although the literature on expectant fathers who experienced childhood trauma is scant, we can assume they have similar challenges given that $10 \%$ of men in the general population experience significant psychological distress after the birth of a child..$^{20}$ Moreover, childhood maltreatment is associated with important long-term consequences in men as well as women. ${ }^{21}$

Risk trajectories associated with early experiences of abuse and neglect may be transmitted from one generation to the next. For instance, early in their development, the majority of children born to a mother with a personal history of abuse or neglect develop insecure attachment strategies $(82 \%$ vs $38 \%$ of the general population) and as many as $44 \%$ (vs $15 \%$ of the general population) display disorganized/disoriented attachment. ${ }^{22}$ Disorganized attachment is a significant precursor of social, intellectual, cognitive, affective and behavioural difficulties. ${ }^{23,24}$ Children of mothers with personal histories of trauma are also at greater risk of presenting with developmental problems such as biological anomalies in the physiological regulation of stress $^{25-27}$, neurodevelopmental disorders ${ }^{10}$ and emotional and behavioural problems. ${ }^{18,28-30}$ In addition, empirical evidence supports the notion of intergenerational cycles of childhood maltreatment. ${ }^{31-33}$

Given the high prevalence (32\%) of reported child maltreatment in Canada, ${ }^{21} \mathrm{a}$ significant number of expectant parents have a personal history of abuse or neglect. Considering (1) the multiple challenges expectant parents encounter during the transition to parenthood; (2) the empirical evidence for the intergenerational transmission of risk following childhood trauma; and (3) the fact that intervening soon after birth may already be late as some intergenerational impacts of parental trauma can be identified immediately after birth ${ }^{25}$, there is a definite need for prenatal interventions specifically designed for this population. Such interventions should aim to promote the physical and mental health of expectant parents who experienced childhood trauma; promote the psychosocial development of their child; and interrupt intergenerational cycles of abuse and neglect.

Different programs are offered worldwide to support parents considered at "highrisk": the Nurse-Family Partnership, ${ }^{34}$ Circle of Security, ${ }^{35}$ Early Start $^{36}$ or Minding the Baby. ${ }^{37}$ The program with the strongest evidence for preventing childhood maltreatment is the Nurse-Family Partnership. ${ }^{38}$ All of these programs generally include home visitations and mainly target adults who have difficulties responding to infant needs or who present general risk factors (e.g. adolescent motherhood, poverty, drug use). However, they are not specifically designed to address the particular challenges associated with the experience of childhood trauma or do not evaluate their effects in parents with histories of abuse or neglect. ${ }^{39}$

Conceptualizing specific interventions for this population may be important, as the way adults with histories of abuse or neglect view their experiences plays a distinctive role in their adaptation to parenthood and in the attachment relationship they develop with their child.,22 A recent literature review confirmed that there are currently very few perinatal interventions for parents with histories of trauma and that no intervention was evaluated with fathers. ${ }^{39}$ Many of the programs listed above are designed to intervene primarily during the postnatal period. Only two programs specifically designed for adults with histories of trauma are delivered primarily during pregnancy: Survivor Moms Companion, a self-help manual, ${ }^{40}$ and the Perinatal Child-Parent Psychotherapy, ${ }^{41}$ which involves one-on-one psychotherapy. Prenatal interventions are required for different reasons. First, parents are psychologically and physically more available during this period than after the birth of the child. It has been suggested that pregnancy invariably activates internalized attachment representations, ${ }^{42}$ making pregnancy an ideal time for clinical approaches that aim to rework internalized object relationships. ${ }^{43}$ From a practical stance, parents may be unavailable to participate in interventions after the child's birth, when obligations and responsibilities are numerous. Overall, perinatal interventions for parents who experienced interpersonal traumas in childhood were safe and acceptable to parents, but further research is required.

Sensitive parenting may require that someone has previously been sensitive to the parent's own history and psychological conflicts. Based on this reasoning, prenatal interventions offer the opportunity to sensitively accompany the person in the development of their identity as a parent, while the focus of postnatal interventions can be placed on the child and the parent-child relationship. As well, intervening in the postnatal period, however early, may be considered more therapeutic than preventive as intergenerational impacts of childhood maltreatment are observed immediately after the child's birth ${ }^{25}$ and important problems in the mother-child attachment relationship may already be in place at the time of consultation. ${ }^{22}$ Prenatal interventions would complement existing postnatal programs in preventing the emergence of difficulties in the parent-child relationship and may help interrupt the intergenerational transmission of risk associated with childhood maltreatment. 
Considering the lack of prenatal interventions for adults with personal histories of childhood maltreatment, the aim of the present study was to consult health care providers and community organizations about the actions that should be taken during a prenatal group intervention designed to help expectant parents who experienced childhood trauma.

\section{Methods}

\section{Delphi consensus development method}

The Delphi consensus development method was used to identify important actions that should be accomplished during a prenatal group intervention for expectant parents who experienced childhood abuse or neglect. The Delphi method is widely used by health care professionals to determine sets of priorities in relation to health practice and research, ${ }^{44,45}$ and it has been previously used to establish guidelines on how to support people with personal histories of trauma. ${ }^{46}$

The goal of the Delphi method is to reach a consensus among a panel of experts on a specific domain. Consensus is reached using a series of questionnaires that experts complete in two or more rounds. After each round, the results are summarized and the experts are invited to discuss their responses. A revised questionnaire is then presented and the participants are encouraged to re-evaluate their earlier answers in light of the discussions. This process eventually leads to a decrease in the variance in experts' ratings of priorities in a domain and the achievement of a consensus about a certain number of priorities.

\section{Supporting the transition to and engagement in parenthood (STEP)}

STEP is a clinical research program carried out at the Université du Québec à Trois-Rivières and funded by the Public Health Agency of Canada. The aim is to design, deliver and evaluate an innovative group accompaniment program for expectant parents who experienced interpersonal trauma in childhood. Ultimately, the aim of the program is to (1) promote the physical and mental health of adults with histories of childhood trauma who are transitioning to parenthood; (2) promote the psychosocial development of the program participants' children; and (3) interrupt intergenerational cycles of abuse.
The present study reports on the first steps of the program's development (see Figure 1). The program is designed for adults with histories of abuse or neglect who either do or do not present with or currently experience psychosocial difficulties. The program aims to complement existing interventions and services for expectant parents and promote participation of parents with histories of childhood trauma in such services.

\section{Participants}

The research was initiated by three project leaders who are clinical psychologists and researchers in the fields of mental health, child development and parenting. The research also involved 18 partners from 10 independent organizations that offer services to expectant parents, families and/or other adults who experienced

FIGURE 1

Framework of the development and evaluation of the STEP accompaniment program

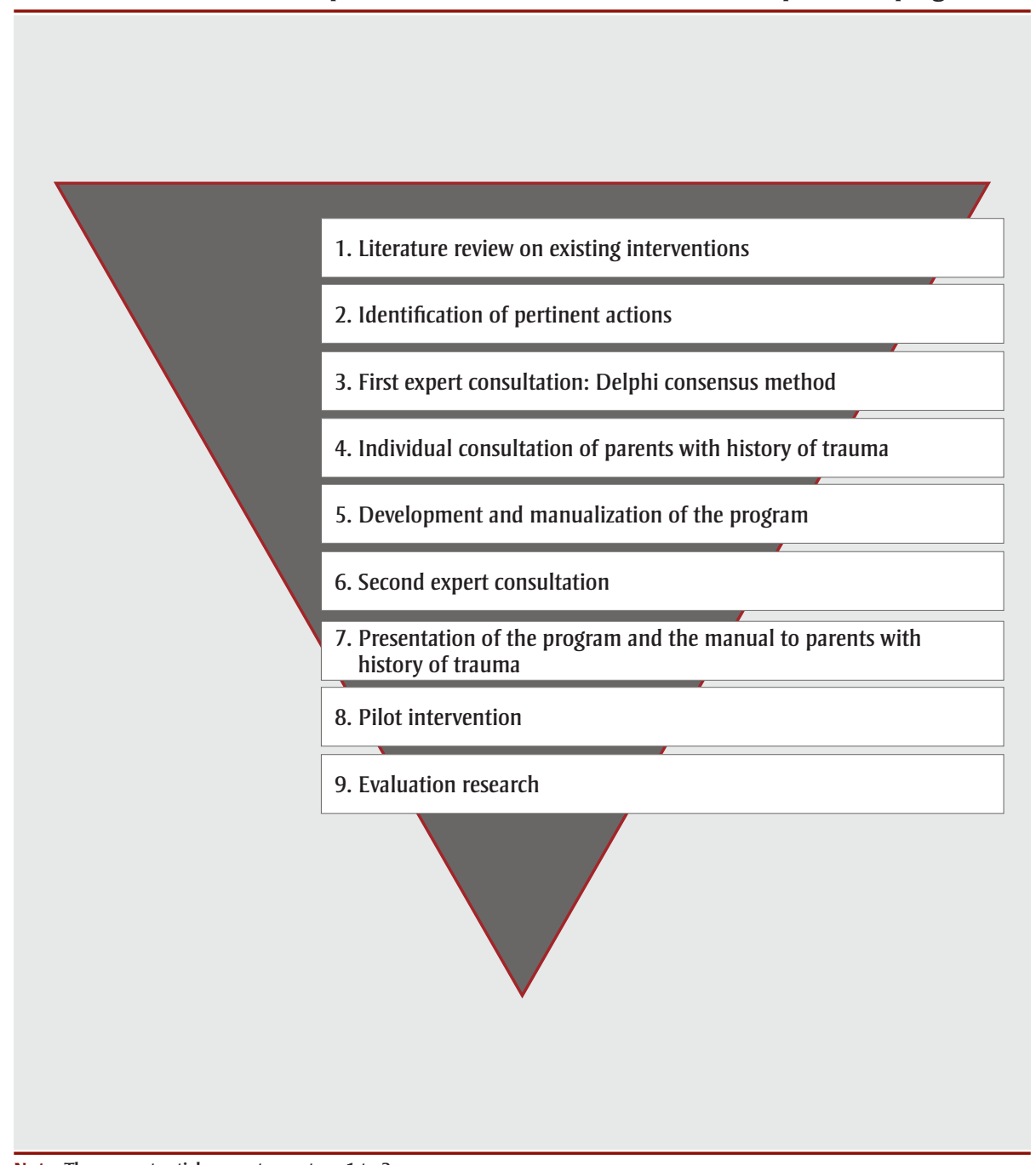

Note: The current article reports on steps 1 to 3. childhood trauma. Three of these 18 stakeholders identified themselves as more or less qualified to complete the Delphi consensus development process, but one had to withdraw to take maternity leave. Fifteen professionals from nine organizations participated in the first round of consultations, 15 in the in-person discussions and 14 in the final round of consultations. All participants were franholders were selected by the project leaders for their expertise in childhood trauma; childhood sexual abuse; parental neglect; intimate partner violence; pregnancy, childbirth and delivery; parenting in the context of vulnerabilities; parentchild relationships; fatherhood; prevention of child abuse and neglect; child protection; Indigenous communities; individual psychotherapy with survivors of trauma; group intervention; health care cophone and worked in Quebec. Stake. . 
management; community services; health care; and program evaluation. Table 1 provides more information on the participants.

\section{Procedure}

After reviewing clinical and empirical literature on parenting interventions and interventions with parents and victims of trauma, the three project leaders first identified a preliminary list of actions to accomplish during a prenatal group intervention with adults with personal histories of childhood trauma. The selected actions had to be particularly pertinent to adults with histories of interpersonal trauma, and sufficiently appropriate and safe to be conducted during pregnancy. Following the team discussions, the project leaders identified six core themes that they determined to be important for expectant parents who are trauma survivors: attachment; mentalization (the ability to think of behaviours in terms of underlying mental states such as emotions, motivations or beliefs); transition to parenthood; emotion regulation; trauma; and social support. A starting list of 36 potential actions covering these core themes was proposed. The preliminary list of actions is presented in Table 2 .

The participants in the consultation process were first requested to rate in terms of importance the proposed actions using an anonymized online survey. A five-point Likert scale was used ( 1 = not important; 2 = somewhat important; 3 = important; 4 = very important; 5 = essential). Participants were also asked to propose additional actions and to identify the extent to which each action was being accomplished in their clinical setting using a five-point Likert scale $(1=$ different from existing services; 2 = slightly different from existing services; 3 = I don't know if such an action is offered in my clinical setting; 4 = similar to existing services; 5 = identical to existing services).

This first round of the consultation process was followed by a one-day in-person meeting during which the results of the first round were presented and each action was discussed. Participants were invited to comment on their responses, to discuss the feasibility of these interventions and to identify the extent to which they replicate services already available to expectant

TABLE 1

Participants in the STEP program development Delphi consensus

\begin{tabular}{lll}
\multicolumn{1}{c}{ Work setting } & \multicolumn{1}{c}{ Training } & \multicolumn{1}{c}{ Primary occupation } \\
\hline Academic & Clinical psychology & Researcher \\
Academic & Clinical psychology & Researcher \\
Academic & Clinical psychology & Researcher \\
Academic & Clinical psychology & Service to the population \\
Academic & Pediatric nursing & Researcher \\
Academic & Perinatal nursing & Researcher \\
Governmental agency & Social work & Service to the population \\
Governmental agency & Nursing & Coordination of services \\
Governmental agency & Social work and management & Coordination of services \\
Governmental agency & Psychoeducation & Coordination of services \\
Non-governmental organization & Social work & Coordination of services \\
Non-governmental organization & Psychoeducation & Coordination of services \\
Non-governmental organization & Social work & Coordination of services \\
\hline Non-governmental organization & Law & Coordination of services \\
\hline Non-governmental organization & Psychoeducation & Service to the population \\
Non-governmental organization & Psychology & Service to the population \\
Non-governmental organization & Animation and training & Service to the population \\
Non-governmental organization & Animation and administration & Service to the population \\
Non-governmental organization & Midwifery & Service to the population \\
\hline
\end{tabular}

Abbreviation: STEP, Supporting the transition to and engagement in parenthood. parents in the participants' own clinical practices. The discussions were recorded and used to refine the actions and to prepare a final list. One week after the meeting, participants received the revised list through a second online survey and were requested to code for a second time the importance they attributed to each action.

Ethical approval for the study was given by the Comité d'éthique de la recherche avec des êtres humains de l'Université du Québec à Trois-Rivières (CER15-226-10.04) and the Comité d'éthique de la recherche du Centre intégré universitaire de santé et de services sociaux de la Mauricie-et-duCentre-du-Québec (CER2016-016-00).

\section{Results}

\section{Round 1 (online survey)}

A total of 15 stakeholders completed the first round of consultations. The results are presented in Table 2. Overall, each dimension was considered important. Topranked themes for discussion included attachment relationships, followed by social support, mentalization, trauma, transition to parenthood and emotional regulation. All actions obtained an average score of over 3, indicating their importance in the context of working with expectant parents who experienced trauma in childhood. While the themes of attachment relationships and social support were rated by the experts as the most important, they were also more likely to be offered in existing services compared with those actions that aim to help people process the trauma and improve mentalization, which appear more innovative.

\section{In-person meeting}

Fifteen participants attended the one-day discussion meeting. The relevance, feasibility and implementation of each action were discussed to refine them. Overall, the group agreed on some general considerations. One of those considerations was that all actions that implied a passive role in participants (teaching, informing, etc.) had to be redefined in order to involve participants actively in the intervention and to make sure that the professionals delivering the program do not present themselves as experts with solutions that have to be implemented by the parents. In other words, rather than providing information or teaching skills, the intervention should aim to support participants' sense 
TABLE 2

Preliminary list of actions for prenatal group intervention prior to Delphi consensus development

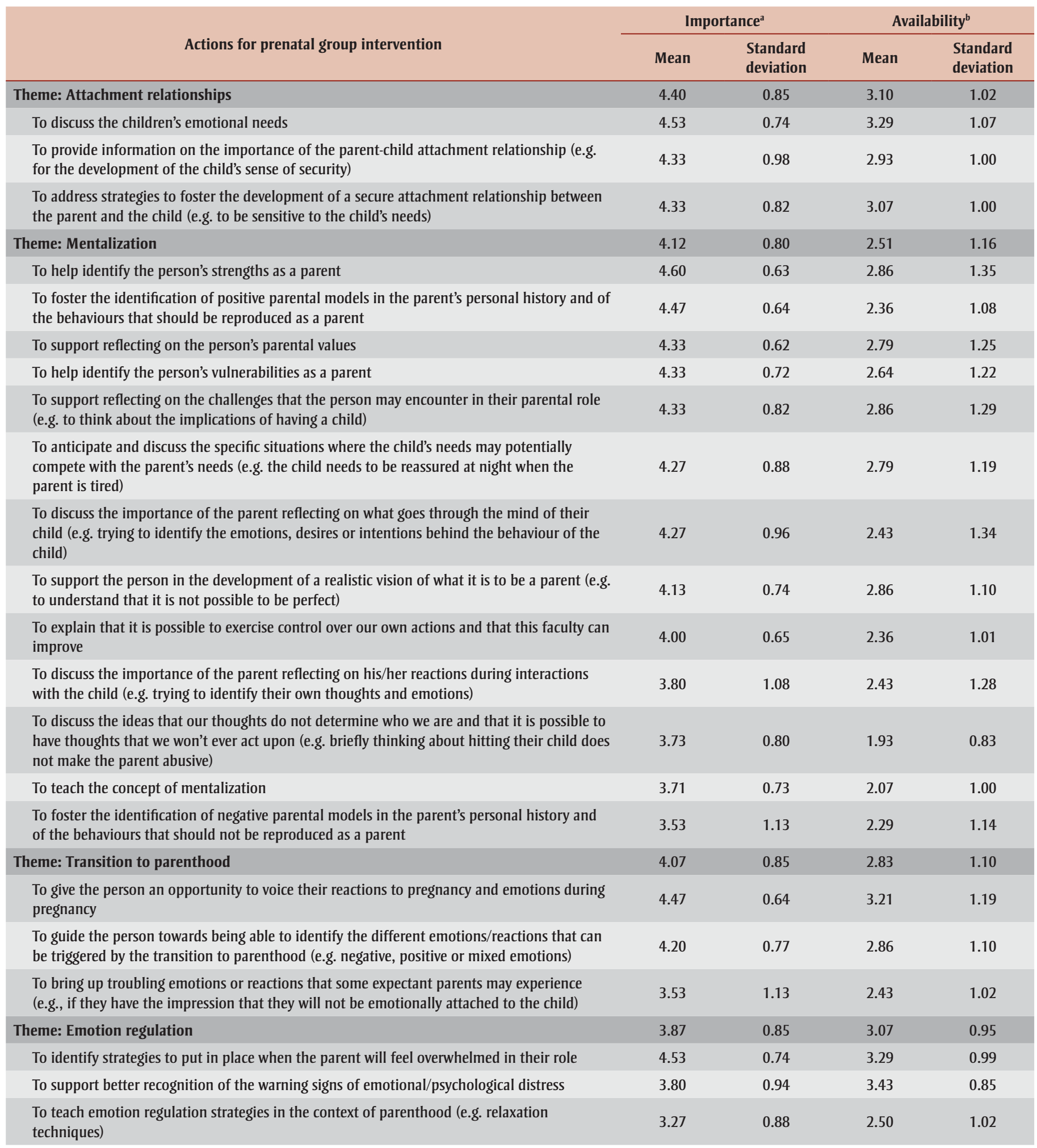

Continued on the following page 
TABLE 2 (continued)

Preliminary list of actions for prenatal group intervention prior to Delphi consensus development

\begin{tabular}{|c|c|c|c|c|}
\hline \multirow[b]{2}{*}{ Actions for prenatal group intervention } & \multicolumn{2}{|c|}{ Importance $^{\mathrm{a}}$} & \multicolumn{2}{|c|}{ Availability } \\
\hline & Mean & $\begin{array}{l}\text { Standard } \\
\text { deviation }\end{array}$ & Mean & $\begin{array}{l}\text { Standard } \\
\text { deviation }\end{array}$ \\
\hline Theme: Trauma & 4.07 & 0.87 & 2.49 & 1.28 \\
\hline $\begin{array}{l}\text { To discuss the importance of protection in order to be safe and keep the child safe (e.g. to } \\
\text { help the person to more effectively identify the contexts that will potentially place them at } \\
\text { risk or place the child at risk) }\end{array}$ & 4.40 & 0.74 & 2.79 & 1.19 \\
\hline $\begin{array}{l}\text { To discuss how the unmet needs and frustrations of the adult victim of childhood maltreat- } \\
\text { ment can emerge in their adult/parenting life (e.g. the need to feel adequate, the need to feel } \\
\text { in control) }\end{array}$ & 4.40 & 0.74 & 2.43 & 1.02 \\
\hline $\begin{array}{l}\text { To discuss the potential impacts of the trauma on the adult's perception and identity as a } \\
\text { parent (e.g. to continue to see himself/herself as a victim, to see the child's behaviours as } \\
\text { malevolent) }\end{array}$ & 4.27 & 0.80 & 2.50 & 1.09 \\
\hline $\begin{array}{l}\text { To assist the person in identifying the normal childhood needs that were not met during the } \\
\text { person's own childhood }\end{array}$ & 4.27 & 0.88 & 2.36 & 1.34 \\
\hline $\begin{array}{l}\text { To inform about the potential impacts of trauma in the context of parenting (e.g. fear of } \\
\text { repeating the trauma experienced, not being alert to risky situations) }\end{array}$ & 4.20 & 0.86 & 2.43 & 1.40 \\
\hline $\begin{array}{l}\text { To discuss the coping strategies often used by victims of maltreatment to protect themselves } \\
\text { from the feelings and memories associated with the trauma (e.g. avoidance behaviours) }\end{array}$ & 3.93 & 0.96 & 2.43 & 1.50 \\
\hline $\begin{array}{l}\text { To provide information on the impacts of trauma (e.g. biological impacts, intense emotions, } \\
\text { negative self-perception and of others, sense of insecurity) }\end{array}$ & 3.80 & 0.94 & 2.57 & 1.45 \\
\hline $\begin{array}{l}\text { To discuss the potential harmful effects on the parent and the child of behaviours or } \\
\text { strategies commonly used to alleviate trauma-associated distress (e.g. alcohol or drug use/ } \\
\text { abuse, dissociation, avoidance) and to offer clues for alternative solutions }\end{array}$ & 3.73 & 0.96 & 2.50 & 1.22 \\
\hline To identify the various situations that may cause trauma & 3.60 & 0.99 & 2.43 & 1.34 \\
\hline Theme: Social support & 4.23 & 0.73 & 3.43 & 0.91 \\
\hline To create an opportunity to seek support from community organizations & 4.40 & 0.63 & 3.64 & 1.01 \\
\hline To suggest strategies to reinforce the parent's social network & 4.27 & 0.59 & 3.64 & 0.74 \\
\hline To create an opportunity to seek professional support & 4.27 & 0.70 & 3.64 & 0.93 \\
\hline To discuss the importance of both parents for the child, even when one is less involved & 4.13 & 0.83 & 3.36 & 0.93 \\
\hline $\begin{array}{l}\text { To offer strategies to strengthen the parental couple or to discuss how to face the challenges } \\
\text { of lone parenting }\end{array}$ & 4.07 & 0.88 & 2.86 & 0.95 \\
\hline
\end{tabular}

${ }^{a}$ Based on a 5-point Likert scale where 1 = not important; 2 = somewhat important; $3=$ important; 4 = very important; $5=$ essential.

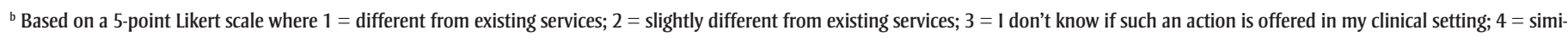
lar to existing services; 5 = identical to existing services.

of competence and personal agency. Another consideration was that the actions should not try to identify deficiencies, but rather should be formulated as opportunities for self-development for all expectant parents. In other words, the program should be presented as an "accompaniment program" rather than as an "intervention." The group also agreed that the program should listen to and address participants' needs before discussing the children's needs-the focus should first be on the "developing parents" and later on the "developing children." Stimulating sensitive parenting cannot be accomplished without being sensitive to parents' personal history, reality and internal conflicts. In addition, the actions had to be gender-specific rather than gender-neutral, and thus be delivered differently to men and women.

Overall, the group recommended that the program be designed in a way that helps participants gain awareness of their personal strengths and weaknesses; to think, in a compassionate fashion, about how their past experiences influence how they perceive themselves as person and a parent today; and to be sensitive to issues relevant to the experiences of expectant mothers and fathers. As a result, mentalization was reconsidered from being a specific dimension to address with future participants to being the core framework of the intervention. The six themes were thus regrouped in two broader categories: (1) actions with the aim of stimulating participants' mentalization about themselves and their experience of parenthood; and (2) actions with the aim of stimulating participants' mentalization about their adverse life experiences.

\section{Round 2 (online survey)}

Actions were refined by the project leaders and a final list of 22 (15 actions on mentalizing self and parenthood and 7 on mentalizing trauma) was sent to the stakeholders in an online survey. Fourteen participants completed this final round anonymously. The results, ranked in order of importance, are presented in Table 3. 
TABLE 3

Final list of actions for prenatal group intervention after Delphi consensus development

\begin{tabular}{|c|c|c|c|}
\hline $\begin{array}{l}\text { Overall } \\
\text { ranking }\end{array}$ & Actions for prenatal group intervention & Mean $^{\mathrm{a}}$ & $\begin{array}{l}\text { Standard } \\
\text { deviation }\end{array}$ \\
\hline \multicolumn{4}{|c|}{ Theme 1 - Mentalization of self and parenthood } \\
\hline 1 & $\begin{array}{l}\text { To discuss the specific situations where the person's needs will potentially compete with the child's needs (e.g. the child is } \\
\text { in need of reassurance at night when the parent is tired) }\end{array}$ & 4.50 & 0.65 \\
\hline 3 & $\begin{array}{l}\text { To support the person in elaborating a realistic version of what it is to be a parent (e.g. to understand it is not possible to } \\
\text { be perfect) }\end{array}$ & 4.46 & 0.66 \\
\hline 4 & $\begin{array}{l}\text { To support reflecting on the signs of emotional distress and to discuss the available forms of support (e.g. emotional, ma- } \\
\text { terial assistance, coaching, physical assistance, socialization) that are the most appropriate for the person's specific needs }\end{array}$ & 4.43 & 0.85 \\
\hline 5 & $\begin{array}{l}\text { To guide the person in identifying the different emotions/reactions arising as a response to parenting in general and for } \\
\text { this person specifically, and to offer a place to voice opinions on these emotions (negative, positive or mixed emotions) }\end{array}$ & 4.36 & 0.63 \\
\hline 6 & To support reflecting on the person's strengths and weaknesses as a parent & 4.36 & 0.50 \\
\hline 8 & $\begin{array}{l}\text { To reflect on the emotional needs of children and what these needs may trigger in the parent in terms of emotions, } \\
\text { thoughts and behaviours }\end{array}$ & 4.29 & 0.61 \\
\hline 9 & $\begin{array}{l}\text { To support reflecting on the typical challenges that parents encounter and to help identify those that this person is } \\
\text { inclined to meet in their parental role }\end{array}$ & 4.29 & 0.83 \\
\hline 11 & $\begin{array}{l}\text { To foster the identification of positive as well as negative parental models in the person's personal history and to reflect } \\
\text { on the influence of these models on the person's perception of parenthood and on the future relationship with the child }\end{array}$ & 4.21 & 0.97 \\
\hline 12 & $\begin{array}{l}\text { To support reflecting on the intentions and motivations underlying the behaviours of the child and to discuss contexts } \\
\text { that may influence the person's interpretation of the child behaviours }\end{array}$ & 4.21 & 0.70 \\
\hline 13 & To support reflecting on the person's values as a parent & 4.14 & 0.77 \\
\hline 14 & $\begin{array}{l}\text { To support reflecting on the affective, cognitive and behavioural strategies that the person is considering using when } \\
\text { feeling destabilized after the arrival of the child }\end{array}$ & 4.14 & 0.86 \\
\hline 17 & To support reflecting on the parent's social network & 4.00 & 0.68 \\
\hline 18 & To support reflecting on the importance of both parents for the child, even when one of them is less involved & 3.93 & 0.83 \\
\hline 19 & To support reflecting on parents' relationships in the context of parenthood and on the experience of being a lone parent & 3.79 & 0.80 \\
\hline 22 & $\begin{array}{l}\text { To discuss psychological functioning by illustrating its principles with concrete examples (e.g. it is possible to exercise } \\
\text { control over our own actions and that this faculty can be improved; our thoughts do not determine who we are, and it is } \\
\text { possible to have thoughts that we won't ever act upon) }\end{array}$ & 3.57 & 1.09 \\
\hline \multicolumn{4}{|c|}{ Theme 2 - Mentalization of trauma } \\
\hline 2 & To discuss the potential impacts of trauma in the context of parenting (e.g. fear of repeating the trauma) & 4.50 & 0.65 \\
\hline 7 & To stimulate the potential to reach out for help and for community services support & 4.36 & 0.74 \\
\hline 10 & $\begin{array}{l}\text { To discuss the coping strategies often used by victims of maltreatment to protect themselves from the feelings and memo- } \\
\text { ries associated with the trauma (e.g. avoidance behaviours), and to identify how the typical challenges of parenthood } \\
\text { may exacerbate or interfere with the use of such strategies }\end{array}$ & 4.29 & 0.91 \\
\hline 15 & To support reflecting on the contexts that may potentially be a risk for the parent's and for the child's security & 4.14 & 0.77 \\
\hline 16 & $\begin{array}{l}\text { To support identifying the normal childhood needs that were not met during the person's own childhood. To discuss how } \\
\text { these unmet needs can affect typical parenthood challenges (e.g. difficulty in tolerating the child's dependency or, } \\
\text { eventually, their developing autonomy) }\end{array}$ & 4.07 & 0.83 \\
\hline 20 & To identify the various situations that may cause trauma & 3.79 & 1.12 \\
\hline 21 & $\begin{array}{l}\text { To support a discussion on the impacts of trauma on diverse spheres of functioning (e.g. biological impacts, intense } \\
\text { emotions, negative self-perception, sense of insecurity) }\end{array}$ & 3.79 & 1.12 \\
\hline
\end{tabular}

${ }^{\text {a }}$ Based on a 5 -point Likert scale where $1=$ not important; $2=$ somewhat important; 3 = important; $4=$ very important; $5=$ essential. 
Overall, all actions were considered important.

\section{Discussion}

The aim of the present study was to consult with health care providers and community organizations about the actions that should be accomplished by prenatal group programs designed to help adults with personal histories of childhood trauma.

The research led to three main observations. First, we identified very few prenatal interventions specifically designed for expectant women and men who have personal histories of abuse or neglect, despite the long-term and intergenerational consequences associated with these adverse childhood experiences. ${ }^{39}$ Second, our results confirm that health care providers and community organizations consider such an intervention important and a valuable addition to the services they already offer to victims of abuse or expectant parents. Third, the mentalization framework should be considered when developing such a program, with actions aimed at supporting participants' mentalization of their experience of parenthood and mentalization of their adverse childhood experiences.

A focus on mentalization is in accordance with recent clinical and empirical literature. Mentalization-based interventions integrate psychodynamic, cognitive and neurodevelopmental theories. ${ }^{47,48}$ Mentalization-based approaches typically aim to reinforce participants' ability to think of their behaviours and those of others (for instance, their baby) in terms of mental states. While empirical evidence confirms the efficacy of such interventions among adults with severe psychological difficulties ${ }^{49}$ and among parents of young children, ${ }^{50}$ the interventions have never been specifically adapted for expectant parents with personal histories of childhood trauma. Enhancing mentalization could play a major protective role in parents who experienced childhood trauma: mentalization abilities in pregnant women with personal histories of childhood abuse correlate with their engagement in parenthood and with the quality of their couple relationship during pregnancy ${ }^{8}$ and predict the quality of the attachment relationship they develop with their baby. ${ }^{22}$ However, enhancing mentalization in parents for whom the normal development of this ability was disturbed by adverse life circumstances is complex and calls for specific adaptations. ${ }^{51}$

This study adds to the literature on the provision of an empirically and clinically grounded framework for the development of a prenatal accompaniment program aimed at expectant parents who experienced childhood abuse or neglect. The actions identified by the stakeholders during this Delphi process differ from what currently exists in terms of prenatal psychosocial interventions in Quebec. The principal aim of many of the programs offered to the general population is to provide information on pregnancy, child development and child care. These programs, which are mainly informed by social learning theories, focus on enhancing knowledge, skills and confidence in parents through role models, practical exercises and feedback. ${ }^{52}$ Several prenatal programs have been designed for at-risk parents, and many have been shown to lead to significant improvement in parental functioning and to positive outcomes for children. ${ }^{39,52-54}$

However, to the best of our knowledge, few interventions specifically address the unique needs of parents with personal histories of trauma or use a theory of trauma as conceptual framework. Even parenting interventions aimed at preventing childhood maltreatment and trauma are rarely informed by trauma theories. ${ }^{55}$ In other words, these programs do not consider the challenges that face people who grow up in environments where their needs or vulnerabilities were neither considered nor respected in becoming parents and participating in psychosocial interventions.

Public and community services for parents and children represent an institutional space within which several approaches or perspectives coexist. Some of these are contradictory in the actions they offer to families. The implementation of a new service model for expectant parents with histories of trauma must consider this institutional complexity.

\section{Limitations}

This study had some limitations. First, the priorities presented here reflect the perspective of stakeholders in health care and from community organizations and may not reflect the position of adults who will ultimately benefit from such psychosocial programs. Our team is investigating the points of view and specific needs in terms of prenatal interventions of adults with personal histories of childhood trauma. Second, the panel of professionals recruited for this research reflects the diverse range of services offered to victims of abuse or neglect or expectant parents in the region where the study was conducted. A panel recruited elsewhere may have identified other priorities. Third, despite that having 15 professionals involved in this process is a considerable success, the number of participants is relatively small.

\section{Conclusions}

To the best of our knowledge, this paper articulates the first set of priorities for a clinical program aimed at supporting expectant parents with personal histories of childhood trauma. This set of priorities will represent the framework for STEP, a prenatal group program currently under development that, once evaluated and implemented, will be offered to women and men who experienced childhood abuse and neglect. This program may contribute to promoting the physical and mental health of adults with personal histories of childhood trauma who are transitioning to parenthood; promoting the psychosocial development of their children; and interrupting intergenerational cycles of abuse.

\section{Acknowledgements}

The Public Health Agency of Canada contributed financially to this research.

The authors want to thank all stakeholders who participated in this research, as well Christine Drouin-Maziade (project leader), Sylvie Moisan (research coordinator), Aurélie Baker-Lacharité (Masters student) and Vanessa Bergeron (PhD student) for their help in organizing this activity.

\section{Conflict of interest}

The authors have no conflict of interest

\section{Authors's contributions and statement}

NB contributed to the design and conceptualization of the study; to the acquisition, analysis and interpretation of the data; and to drafting the paper. RL contributed to the design and conceptualization of the 
study; to the acquisition, analysis and interpretation of the data; and to revising the paper. CL contributed to the design and conceptualization of the study; to the acquisition of the data; and to revising the paper.

The content and views expressed in this article are those of the authors and do not necessarily reflect those of the Government of Canada.

\section{References}

1. Guedeney A, Tereno S. Transition to parenthood. In: Tyano S, Keren M, Herramn H, Cox J, editors. Parenthood and mental health: a bridge between infant and adult psychiatry. Oxford (UK): Willey-Blackwell Publications; 2010: 171-9. doi: 10.1002 /9780470660683.ch16.

2. Cecil CA, Viding E, Fearon P, Glaser D, McCrory EJ. Disentangling the mental health impact of childhood abuse and neglect. Child Abuse Negl. 2017;63:106-19. doi: 10.1016/j.chiabu .2016.11.024.

3. Teicher MH, Samson JA. Childhood maltreatment and psychopathology: a case for ecophenotypic variants as clinically and neurobiologically distinct subtypes. Am J Psychiatry. 2013; 170(10):1114-33. doi: 10.1176/appi.ajp .2013 .12070957 .

4. Banyard V, Hamby S, Grych J. Health effects of adverse childhood events: identifying promising protective factors at the intersection of mental and physical well-being. Child Abuse Negl. 2017;65:88-98. doi: 10.1016/j .chiabu.2017.01.011.

5. Afifi TO, MacMillan HL, Boyle M, et al. Child abuse and physical health in adulthood. Health Rep. 2016;27(3): 10-8.

6. Berthelot N, Ensink K, DrouinMaziade C. Les défis de la parentalité pour les victimes de mauvais traitements au cours de leur enfance. In: Giraudeau C, editor. Éléments pour une psychologie de la maltraitance. Paris: Editions Publibook Université; 2016. p. 53-76
7. Raphael-Leff J. Mothers' and fathers' orientations: patterns of pregnancy, parenting and the bonding process. In: Tyano S, Keren $\mathrm{M}$, Herrman $\mathrm{H}$, Cox J, editors. Parenthood and mental health: a bridge between infant and adult psychoatry. West Sussez (UK): Wiley-Blackwell; 2010: 9-22. doi: 10.1002/9780470660683.ch1.

8. Ensink K, Berthelot N, Bernazzani O, Normandin L, Fonagy P. Another step closer to measuring the ghosts in the nursery: preliminary validation of the Trauma Reflective Functioning Scale. Front Psychol. 2014;5:1471. doi: 10.3389/fpsyg.2014.01471.

9. Lukasse M, Schei B, Vangen S, Øian P. Childhood abuse and common complaints in pregnancy. Birth. 2009; 36(3):190-9. doi: 10.1111/j.1523-536X .2009.00323.x.

10. Roberts AL, Lyall K, Rich-Edwards JW, Ascherio A, Weisskopf MG. Association of maternal exposure to childhood abuse with elevated risk for autism in offspring. JAMA Psychiatry. 2013;70(5):508-15. doi: 10.1001/jamapsychiatry.2013.447.

11. Yampolsky L, Lev-Wiesel R, Ben-Zion IZ. Child sexual abuse: is it a risk factor for pregnancy? J Adv Nurs. 2010;66(9):2025-37.

12. Huth-Bocks AC, Krause K, AhlfsDunn S, Gallagher E, Scott S. Relational trauma and posttraumatic stress symptoms among pregnant women. Psychodyn Psychiatry. 2013; 41(2):277-301. doi: 10.1521/pdps.2013 .41 .2 .277 .

13. Nelson DB, Uscher-Pines L, Staples SR, Grisso JA. Childhood violence and behavioral effects among urban pregnant women. J Womens Health (Larchmt). 2010;19(6):1177-83. doi: 10.1089/jwh.2009.1539.

14. Seng JS, Low LK, Sperlich M, Ronis DL, Liberzon I. Prevalence, trauma history, and risk for posttraumatic stress disorder among nulliparous women in maternity care. Obstet Gynecol. 2009;114(4):839-47. doi: 10.1097/AOG.0b013e3181b8f8a2.
15. Lang AJ, Rodgers CS, Lebeck MM. Associations between maternal childhood maltreatment and psychopathology and aggression during pregnancy and postpartum. Child Abuse Negl. 2006;30(1):17-25. doi: 10.1016/j .chiabu.2005.07.006.

16. Seng JS, Sperlich M, Low LK. Mental health, demographic, and risk behavior profiles of pregnant survivors of childhood and adult abuse. J Midwifery Womens Health. 2008;53(6):511-21. doi: 10.1016/j.jmwh.2008.04.013.

17. Berlin LJ, Appleyard K, Dodge KA. Intergenerational continuity in child maltreatment: mediating mechanisms and implications for prevention. Child Dev. 2011;82(1):162-76. doi: 10.1111/j.1467-8624.2010.01547.x.

18. Min MO, Singer LT, Minnes S, Kim H, Short E. Mediating links between maternal childhood trauma and preadolescent behavioral adjustment. J Interpers Violence. 2013;28(4):83151. doi: $10.1177 / 0886260512455868$.

19. Ruscio AM. Predicting the child-rearing practices of mothers sexually abused in childhood. Child Abuse Negl. 2001;25(3):369-87. doi: 10.1016 /S0145-2134(00)00252-0.

20. Giallo R, D’Esposito F, Cooklin A, et al. Psychosocial risk factors associated with fathers' mental health in the postnatal period: results from a population-based study. Soc Psychiatry Psychiatr Epidemiol. 2013;48(4):56373. doi: 10.1007/s00127-012-0568-8.

21. Afifi TO, MacMillan HL, Boyle M, Taillieu T, Cheung K, Sareen J. Child abuse and mental disorders in Canada. Can Med Assoc J. 2014;186(9):E32432. doi: 10.1503/cmaj.131792.

22. Berthelot N, Ensink K, Bernazzani O, Normandin L, Luyten P, Fonagy P. Intergenerational transmission of attachment in abused and neglected mothers: the role of trauma-specific reflective functioning. Infant Ment Health J. 2015;36(2):200-12. doi: 10.1002/imhj.21499.

23. Lyons-Ruth K, Alpern L, Repacholi B. Disorganized infant attachment classification and maternal psychosocial problems as predictors of hostileaggressive behavior in the preschool classroom. Child Dev. 1993;64(2):57285. doi: $10.2307 / 1131270$. 
24. Green J, Goldwyn R. Annotation: attachment disorganisation and psychopathology: new findings in attachment research and their potential implications for developmental psychopathology in childhood. J Child Psychol Psychiatry. 2002;43(7):835-46. doi: 10.1111/1469-7610.00102.

25. Buss C, Entringer S, Moog NK, et al. Intergenerational transmission of maternal childhood maltreatment exposure: implications for fetal brain development. J Am Acad Child Adolesc Psychiatry. 2017;56(5):373-82. doi: 10.1016/j.jaac.2017.03.001.

26. Brand SR, Brennan PA, Newport DJ, Smith AK, Weiss T, Stowe ZN. The impact of maternal childhood abuse on maternal and infant HPA axis function in the postpartum period. Psychoneuroendocrinology. 2010;35(5): 686-93. doi: 10.1016/j.psyneuen.2009 .10.009.

27. Jovanovic T, Smith A, Kamkwalala A, et al. Physiological markers of anxiety are increased in children of abused mothers. J Child Psychol Psychiatry. 2011;52(8):844-52. doi: 10.1111/j.1469 $-7610.2011 .02410 . x$.

28. Myhre MC, Dyb GA, Wentzel-Larsen T, Grøgaard JB, Thoresen S. Maternal childhood abuse predicts externalizing behaviour in toddlers: A prospective cohort study. Scand J Public Health. 2014;42(3):263-9. doi: 10.1177 /1403494813510983.

29. Plant DT, Barker ED, Waters CS, Pawlby S, Pariante CM. Intergenerational transmission of maltreatment and psychopathology: the role of antenatal depression. Psychol Med. 2013;43(3):519-28. doi: 10.1017/ S0033291712001298.

30. Collishaw S, Dunn J, O’Connor TG, Golding J; Avon Longitudinal Study of Parents and Children Study Team. Maternal childhood abuse and offspring adjustment over time. Dev Psychopathol. 2007;19(2):367-83. doi: $10.1017 /$ S0954579407070186.

31. Ertem IO, Leventhal JM, Dobbs S. Intergenerational continuity of child physical abuse: how good is the evidence? Lancet. 2000;356(9232):814-9. doi: 10.1016/S0140-6736(00)02656-8.
32. Bartlett JD, Kotake C, Fauth R, Easterbrooks MA. Intergenerational transmission of child abuse and neglect: do maltreatment type, perpetrator, and substantiation status matter? Child Abuse \& Neglect. 2017; 63:84-94. doi: 10.1016/j.chiabu.2016 .11 .021 .

33. Schofield TJ, Lee RD, Merrick MT. Safe, stable, nurturing relationships as a moderator of intergenerational continuity of child maltreatment: a meta-analysis. J Adolesc Health. 2013;53 (4 Suppl):S32-8. doi: 10.1016/j .jadohealth.2013.05.004.

34. Olds DL. The nurse-family partnership: an evidence-based preventive intervention. Infant Ment Health $\mathrm{J}$. 2006;27(1):5-25. doi: 10.1002/imhj.20077.

35. Powell B, Cooper G, Hoffman K, Marvin B. The Circle of Security intervention: enhancing attachment in early parent-child relationships. New York (NY): The Guilford Press; 2014.

36. Fergusson DM, Grant H, Horwood LJ, Ridder EM. Randomized trial of the Early Start program of home visitation: parent and family outcomes. Pediatrics. 2006;117(3):781-6. doi: 10.1542/peds.2005-1517.

37. Sadler LS, Slade A, Mayes LC. Minding the Baby ${ }^{\circledR}$ : A mentalizationbased parenting program. Chapter 14 . In: Fonagy P, Allen JG, editors. Handbook of mentalization-based treatment. Chichester (UK): Wiley; 2006:271-88. doi: 10.1002/9780470712986.ch14.

38. Macmillan HL, Wathen CN, Barlow J, Fergusson DM, Leventhal JM, Taussig HN. Interventions to prevent child maltreatment and associated impairment. Lancet. 2009;373(9659):250-66. doi: 10.1016/S0140-6736(08)61708-0.

39. Stephenson LA, Beck K, Busuulwa P, et al. Perinatal interventions for mothers and fathers who are survivors of childhood sexual abuse. Child Abuse Negl. 2018;80:9-31. doi: 10.1016 /j.chiabu.2018.03.018.

40. Rowe H, Sperlich M, Cameron H, Seng J. A quasi-experimental outcomes analysis of a psychoeducation intervention for pregnant women with abuse-related posttraumatic stress. J Obstet Gynecol Neonatal Nurs. 2014; 43(3):282-93. doi: 10.1111/1552-6909 .12312 .
41. Narayan AJ, Bucio GO, Rivera LM, Lieberman AF. Making sense of the past creates space for the baby: Perinatal Child-Parent Psychotherapy for Pregnant Women with Childhood Trauma. Zero Three. 2016;36(5):22-8.

42. Slade A, Cohen LJ, Sadler LS, Miller M. The psychology and psychopathology of pregnancy: reorganization and transformation. In: Zeanah $\mathrm{CH}$, editor. Handbook of infant mental health. 3rd Edition ed. New York (NY): The Guilford Press; 2009: 22-39.

43. Biring GS, Dwyer TF, Huntington DC, Valenstein AF. A study of the psychological processes in pregnancy and the earliest mother-child relationship. Psychoanal Study Child. 1961;16(1):9-44. doi: 10.1080/00797308.1961.

44. Fekri O, Leeb K, Gurevich Y. Systematic approach to evaluating and confirming the utility of a suite of national health system performance (HSP) indicators in Canada: a modified Delphi study. BMJ Open. 2017; 7(4):e014772. doi: 10.1136/bmjopen -2016-014772.

45. Breen LJ, O’Connor M, Calder S, Tai V, Cartwright J, Beilby JM. The health professionals' perspectives of support needs of adult head and neck cancer survivors and their families: a Delphi study. Support Care Cancer. 2017; 25(8):2413-20. doi: 10.1007/s00520 $-017-3647-2$.

46. Kelly CM, Jorm AF, Kitchener BA. Development of mental health first aid guidelines on how a member of the public can support a person affected by a traumatic event: a Delphi study. BMC Psychiatry. 2010;10(1):49. doi: 10.1186/1471-244X-10-49.

47. Allen JG. Mentalizing as a conceptual bridge from psychodynamic to cognitive-behavioral therapies. European Psychotherapy. 2008;8(1):103-21.

48. Allen JG, Fonagy P, Bateman A. Mentalizing in clinical practice. Arlington (VA): American Psychiatric Publishing; 2008.

49. Bateman A, Fonagy P. Randomized controlled trial of outpatient mentalization-based treatment versus structured clinical management for borderline personality disorder. Am J Psychiatry. 2009;166(12):1355-64. doi: 10.1176 /appi.ajp.2009.09040539. 
50. Sadler LS, Slade A, Close N, et al. Minding the Baby: enhancing reflectiveness to improve early health and relationship outcomes in an interdisciplinary home visiting program. Infant Ment Health J. 2013;34(5):391405. doi:10.1002/imhj.21406.

51. Lacharite C, Lafantaisie V. Le rôle de la fonction réflexive dans l'intervention auprès de parents en contexte de négligence envers l'enfant. Rev Que Psychol. 2016;37(3):159-80.

52. MacLeod J, Nelson G. Programs for the promotion of family wellness and the prevention of child maltreatment: a meta-analytic review. Child Abuse Negl. 2000;24(9):1127-49. doi: 10.1016 /S0145-2134(00)00178-2.

53. Kitzman HJ, Olds DL, Cole RE, et al. Enduring effects of prenatal and infancy home visiting by nurses on children: follow-up of a randomized trial among children at age 12 years. Arch Pediatr Adolesc Med. 2010;164(5): 412-8. doi: 10.1001/archpediatrics .2010 .76 .

54. Olds DL, Kitzman HJ, Cole RE, et al. Enduring effects of prenatal and infancy home visiting by nurses on maternal life course and government spending: follow-up of a randomized trial among children at age 12 years. Arch Pediatr Adolesc Med. 2010;164(5): 419-24. doi: 10.1001/archpediatrics .2010 .49 .

55. Barth RP. Preventing child abuse and neglect with parent training: evidence and opportunities. Future Child. 2009; 19(2):95-118. doi: 10.1353/foc.0.0031. 